\title{
AUDIT SISTEM INFORMASI PERPUSTAKAAN UNIVERSITAS KRISTEN PETRA BERDASARKAN STANDAR CONTROL OBJECTIVES FOR INFORMATION AND RELATED TECHNOLOGY (COBIT 4.0)
}

\author{
Oleh : Muhammad Aldi Sujana \\ 155100048 \\ Universitas Mitra Indonesia, Sistem Informasi \\ Muhammadaldisujana.student@umitra.ac.id
}

\begin{abstract}
ABSTRAK
Perpustakaan Universitas Kristen Petra yang berperan sebagai pusat layanan informasi bagi sivitas akademika tidak dapat lepas dari pengaruh teknologi informasi (TI). Untuk memastikan kelangsungan pelayanan informasi maka dibutuhkan sistem keamanan, pengelolaan data, pengelolaan masalah, dan pengelolaan lingkungan fisik yang memadai baik dari segi hardware maupun software. Ketergantungan ini mengakibatkan TI menjadi titik yang paling rawan dalam memastikan kelangsungan pelayanan informasi di perpustakaan. Dalam memastikan sejauh mana dukungan TI terhadap proses bisnis perpustakaan maka perlu diketahui seberapa baikkah kualitas layanan TI. Untuk mengukur kualitas layanan TI di perpustakaan dibutuhkan suatu proses audit.
\end{abstract}

Pada penelitian ini, dilakukan proses audit operasional untuk mengumpulkan data guna menunjang penilaian audit. Pedoman yang digunakan dalam mengukur aspek - aspek tingkat kedewasaan TI ialah COBIT 4.0 pada bagian delivery and support $4,5,10,11$, dan 12 yang terdiri dari pemastian kelangsungan layanan TI, pengelolaan sistem keamanan, pengelolaan masalah, pengelolaan data, dan pengelolaan lingkungan fisik di perpustakaan.

Penelitian ini menghasilkan temuan dan nilai tingkat kematangan TI di perpustakaan. Proses audit membantu perpustakaan dalam mengevaluasi kinerja layanan TI dan memberi masukan untuk perbaikan.

Kata Kunci: Audit Software, COBIT, Metode Kualitatif

\section{ABSTRACT}

Petra Christian University Library which serves as a center of information services for the academic community can not escape the influence of information technology (IT). To ensure the continuity of service, it requires information security systems, data management, problem management, and proper management of the physical environment in terms of both hardware and software. This dependence resulted in IT being the most vulnerable point in ensuring continuity of information services at the library. For ensuring the extent of IT support for business process library, we need to know how well the quality of IT services. To measure the quality of IT services at the library, it needs an audit process.
In this research, the operational audit process is conducted to collect data to support the audit assessment. The 
guidelines which are used in measuring aspects of IT maturity level is COBIT 4.0 on the delivery and support 4, 5, 10, 11, and 12, consisted of ensuring continuity of IT services, security systems management, problem management, data management, and management of the physical environment in library.

The research resulted in findings and the value of IT maturity level in library. Library audit process helps in evaluating the performance of IT services and provides input for improvement

Keywords: Software Audit, COBIT, Qualitative Method

\section{PENDAHULUAN}

Perpustakaan Universitas Kristen Petra telah berdiri sejak tahun 1966, kemudian pada tahun 1977 perpustakaan menempati gedung yang dirancang sebagai kampus Universitas Kristen Petra di Jalan Siwalankerto 121 - 131 dengan menempati empat dari sepuluh lantai yaitu lantai 5 - 8. Kepindahan perpustakaan ke gedung baru ini diiringi dengan peralihan sistem dari manual menuju ke penggunaan software sebagai sistem otomasi perpustakaan terintegrasi dengan nama resminya SPEKTRA yaitu Sistem Informasi Perpustakaan Universitas Kristen Petra. Sistem tersebut awalnya diterapkan untuk mengelola koleksi buku perpustakaan karena banyaknya jumlah koleksi yang dimiliki perpustakaan tidak memungkinkan untuk diolah secara manual.

Seiring perkembangan zaman Perpustakaan Universitas Kristen Petra pun melakukan perluasan akses informasi dengan menyediakan layanan sirkulasi, referensi, akses internet, koleksi audio visual, $C D$-ROM, database jurnal, dan tugas akhir sebagai penunjang studi, ditambah lagi pencarian buku dapat ditelusuri secara online yang mendukung. Ketergantungan inilah yang mengakibatkan IT (Information Technology) menjadi titik yang paling rawan dalam memastikan kelangsungan pelayanan informasi di perpustakaan. Untuk memastikan dukungan TI terhadap proses bisnis perpustakaan berjalan dengan baik maka perlu diketahui seberapa baikkah kualitas layanan TI tersebut. Untuk mengukur kualitas layanan TI di perpustakaan dibutuhkan suatu proses audit.

Sebelumnya memang pernah diadakan suatu penelitian di Perpustakaan Universitas Kristen Petra berdasarkan COBIT 4.0 dan Capability Maturity Model Integration (CMMI) V1.2 tetapi pada domain yang berbeda yaitu Monitoring and Evaluate 
Software. Meskipun demikian, sesungguhnya peranan utama perpustakaan ialah sebagai pusat layanan informasi modern maka seharusnya tingkat pelayanan yang terletak pada bagian Delivery and Support software penting diaudit agar diketahui sejauh mana kinerja layanan yang telah dilakukan Perpustakaan Universitas Kristen Petra bagi penggunanya. Proses audit yang dimaksud meliputi analisis terhadap domain Delivery and Support software berdasarkan COBIT 4.0 yang berhubungan dengan kelangsungan layanan (DS4), keamanan sistem (DS5), masalah yang terjadi (DS10), pengelolaan data (DS11), dan lingkungan fisik (DS12) mengingat sistem tersebut telah berada dalam tahap implementasi.

Tujuan dari penelitian ini adalah untuk melakukan audit operasional terhadap Sistem Informasi Perpustakaan Universitas Kristen Petra (SPEKTRA) untuk menghasilkan analisis perhitungan tingkat kematangan (skala maturity) dan laporan terkait penilaian terhadap kinerja layanan sistem tersebut.

\section{LANDASAN TEORI}

\subsection{Auditing}

Menurut Purwono, auditing adalah sebuah proses sistematis yang dilakukan oleh seseorang yang memiliki kompetensi dan bersikap independen, mengenai perolehan dan penilaian atas bukti secara obyektif, yang dilakukan dengan melakukan pengumpulan dan penilaian atas bukti - bukti informasi yang dapat dikuantikasikan dan terkait pada suatu entitas ekonomi tertentu, berkenaan dengan pernyataan mengenai tindakan - tindakan dan kejadian - kejadian ekonomi dengan tujuan untuk menentukan tingkat kesesuaian antara pernyataan tersebut dengan kriteria yang telah ditetapkan serta untuk mengkomunikasikan hasil - hasilnya kepada pihak - pihak yang berkepentingan. [1]

Sebagaimana dikemukakan oleh Purwono bahwa audit operasional yaitu proses untuk menguji prinsip - prinsip efektivitas dan efisiensi kinerja sebuah organisasi dalam rangka mencapai tujuan organisasi. Pemeriksaan dilakukan terhadap petunjuk dan pelaksanaan operasional pengolahan data, untuk memperoleh gambaran mengenai tingkat efektivitas dan efisiensi kegiatan operasional, sebab salah satu keharusan yang harus dipenuhi dalam pembangunan sebuah sistem adalah harus tetap murah namun tetap terjamin integritasnya, sebagai upaya menjaga efektivitas dan efisiensi operasi. [1]

\subsection{COBIT 4.0}

Menurut Gondodiyoto, COBIT adalah sekumpulan dokumentasi best practices untuk IT Governance yang dapat membantu auditor, manajemen and pengguna (user) untuk menjembatani jarak antara risiko bisnis, kebutuhan kontrol dan permasalahan - permasalahan teknis di dunia TI. [2]

COBIT dikembangkan oleh IT Governance Institute, yang merupakan bagian dari Information Systems Audit and Control Association (ISACA). COBIT memberikan arahan (guidelines) yang berorientasi pada bisnis, karena itu business process owners dan manajer, termasuk juga auditor dan user, diharapkan dapat memanfaatkan guidelines ini dengan sebaikbaiknya.

\subsubsection{Kubus COBIT}

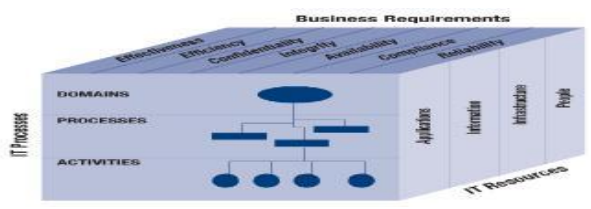

Gambar 1 COBIT Cube

Sumber : IT Governance Institute (2005)

Secara garis besar kubik COBIT terbagi atas tiga

wilayah yaitu kebutuhan bisnis, sumber daya TI, dan proses TI.

1. Kebutuhan Bisnis

Untuk mencapai tujuan bisnis, maka informasi harus sesuai dengan kriteria kontrol yang dispesifikasikan, yang mana oleh COBIT disebut dengan kebutuhan bisnis akan informasi.

2. Sumber Daya TI

Sumber daya TI terdiri dari aplikasi, informasi, infrastruktur, dan orang/personil.

3. Proses TI

Proses TI terbagi atas domain, proses, dan aktivitas. COBIT memiliki empat domain yaitu Plan and Organise, Acquire and Implement, Deliver and Support, dan Monitor and Evaluate yang membantu menggambarkan daur hidup TI. Proses adalah serangkaian aktivitas dan terdapat 34 proses yang berada pada empat domain. Proses ini menjadi spesifikasi pada apa yang bisnis butuhkan untuk mencapai tujuannya. Penyampaian informasi dikontrol melalui 34 proses TI. Aktivitas adalah tindakan yang berkaitan untuk mencapai hasil yang dapat diukur. Aktivitas memiliki daur hidup dan terdiri dari banyak tugas tertentu.

Pada penelitian ini dipilih domain Deliver and Support dengan proses yang diambil yaitu DS 4, 5, 10, 11, dan 12 .

\subsubsection{DS 4 Ensure Continuous Service}

Menurut IT Governance Institute, kebutuhan untuk menyediakan layanan TI terdiri dari pengembangan, pengelolaan, dan pengujian IT Continuity Plans, offsite backup storage, dan pelatihan continuity plan berkala. Kelangsungan layanan yang efektif akan mengurangi probabilitas dan dampak dari gangguan utama yang muncul di layanan TI pada fungsi dan proses bisnis utama. [3]. Bagian ini memiliki 10 detailed control objectives.

\subsubsection{DS 5 Ensure Systems Security}

Menurut IT Governance Institute, kebutuhan untuk mengelola integritas informasi dan perlindungan asset TI membutuhkan proses manajemen keamanan. Proses ini termasuk di dalamnya menetapkan dan mengelola peran dan tanggung jawab keamanan TI, kebijakan, standar, dan prosedur. Manajemen keamanan juga melakukan pengawasan keamanan, pengujian berkala, dan mengimplementasikan tindakan perbaikan untuk kelemahan atau kejadian yang berkaitan dengan keamanan. Proses manajemen keamanan yang efektif akan melindungi semua aset TI untuk mengurangi dampak bisnis dari kerentanan dan kejadian yang berhubungan dengan manajemen keamanan. [3]. Bagian ini memiliki 11 detailed control objectives. 


\subsubsection{DS 10 Manage Problems}

Menurut IT Governance Institute, manajemen masalah yang efektif membutuhkan identifikasi dan klasifikasi dari masalah, root cause analysis, dan resolusi masalah. Pada proses manajemen masalah termasuk di dalamnya mencakup pengidentifikasian rekomendasi untuk peningkatan kinerja, pengelolaan catatan problem dan peninjauan status dari tindakan tindakan yang digunakan untuk perbaikan. Proses manajemen masalah yang efektif meningkatkan tingkat pelayanan, mengurangi biaya yang dikeluarkan, dan meningkatkan kepuasan dan kenyamanan pembeli. [3]. Bagian ini memiliki empat detailed control objectives.

\subsubsection{DS 11 Manage Data}

Menurut IT Governance Institute, manajemen data yang efektif membutuhkan proses identifikasi kebutuhan data. Pada proses manajemen data termasuk di dalamnya terdapat penetapan prosedur secara efektif untuk mengelola media library, data cadangan, pemulihan data, dan pemusnahan media yang benar. Manajemen data yang efektif akan membantu memastikan kualitas, ketepatan waktu, dan akses kapan pun terhadap data bisnis. [3]. Bagian ini memiliki enam detailed control objectives.

\subsubsection{DS 12 Manage the Physical Environment}

Menurut IT Governance Institute, perlindungan terhadap peralatan komputer dan kebutuhan personil membutuhkan fasilitas fisik yang didesain dan dikelola dengan baik. Proses pengelolaan lingkungan fisik termasuk didalamnya dengan menetapkan semua kebutuhan dari wilayah fisik, memilih fasilitas yang tepat dan mendesain proses yang efektif untuk mengawasi faktor lingkungan dan mengelola akses fisik. Manajemen lingkungan fisik yang efektif akan mengurangi interupsi bisnis dari kerusakan peralatan komputer dan personil. [3]. Bagian ini memiliki lima detailed control objectives.

\subsection{Skala Maturity dari COBIT Framework}

Menurut IT Governance Institute, maturity model adalah suatu metode untuk mengukur level pengembangan manajemen proses, yang berarti adalah mengukur sejauh mana kapabilitas manajemen tersebut. Seberapa bagusnya pengembangan atau kapabilitas manajemen tergantung pada tercapainya tujuan - tujuan COBIT. Terkadang ada beberapa proses dan sistem penting yang membutuhkan manajemen keamanan yang lebih ketat dibanding proses dan sistem lain yang tidak begitu penting. Di sisi lain, derajat dan kepuasan pengendalian yang dibutuhkan untuk diaplikasikan pada suatu proses bergantung pada selera resiko perusahaan dan kebutuhan acuan yang diterapkan. [3].

Penerapan yang tepat pada tata kelola TI di suatu lingkungan perusahaan tergantung pada pencapaian tiga aspek maturity (kemampuan, jangkauan, dan kontrol). Peningkatan maturity akan mengurangi resiko dan meningkatkan efisiensi, mendorong berkurangnya kesalahan dan meningkatkan kuantitas proses yang dapat diperkirakan kualitasnya dan mendorong efisiensi biaya terkait dengan penggunaan sumber daya TI.

Menurut IT Governance Institute, tingkat kemampuan pengelolaan TI pada skala maturity dibagi menjadi enam tingkatan, mulai dari level 0 (non-existent), level 1 (initial level), level 2 (repeatable level), level 3 (defined level), level 4 (managed level), level 5 (optimized level). [3].

\subsection{Metode Perhitungan Maturity Level}

Pada penelitian ini, teknik perhitungan nilai audit menggunakan model evaluasi kematangan COBIT yang berdasarkan poin - poin sesuai pencapaian dan kelengkapan proses yang dimiliki perpustakaan. Menurut Pederiva, ada dua hal penting yang perlu dilakukan dalam tahap awal evaluasi yaitu kriteria untuk memilih proses - proses yang dievaluasi dan metode untuk mengukur tingkat kedewasaan organisasi berdasarkan pedoman Model Kedewasaan COBIT. [4]. Metode yang digunakan untuk mengevaluasi ini berbentuk kuesioner yang berasal dari Model Kedewasaan COBIT serta bergantung pada konsep skenario, di mana setiap tingkat kedewasaan dianggap sebagai skenario.

Pederiva mengemukakan bahwa skenario tingkat kedewasaan mencakup deskripsi dari organisasi dan pengontrolan internal perusahaan yang memenuhi persyaratan tingkat kematangan tertentu. [4]. Kuesioner dibuat untuk menangkap kondisi organisasi TI yang tengah diperiksa dengan berbagai skenario yang menggambarkan setiap tingkat kedewasaan. Berdasarkan hasil kuesioner, akan ada algoritma yang digunakan untuk menghitung seberapa besar pencapaian organisasi untuk setiap skenario. Kemudian digunakan vektor untuk menghitung tingkat kematangan rata - rata organisasi untuk masing - masing skenario.

Dalam pembuatan kuesioner, deskripsi dari tingkat kedewasaan yang tertera di Model Kedewasaan COBIT dipelajari. Disimpulkan bahwa setiap deskripsi dari tingkat kedewasaan bisa dilihat sebagai suatu pernyataan yang dapat berdiri sendiri. Setiap deskripsi tingkat kematangan adalah pernyataan yang dapat bernilai benar, sebagian benar, sebagian salah, atau salah. Pemeriksaan ini menghasilkan bahwa nilai pencapaian terhadap standar dapat dihitung untuk setiap tingkat kedewasaan dengan cara mengumpulkan lalu menjumlahkan nilai pencapaian dari setiap pernyataan. Berdasarkan konsep ini, deskripsi tingkat kedewasaan dibagi menjadi pernyataan - pernyataan yang terpisah, dan semua pernyataan dalam deskripsi tingkat kedewasaan itu dipisah dalam kuesioner.

Berikut merupakan contoh bagaimana pernyataan pernyataan kuesioner diturunkan dari model kedewasaan proses PO10 Managing Projects.

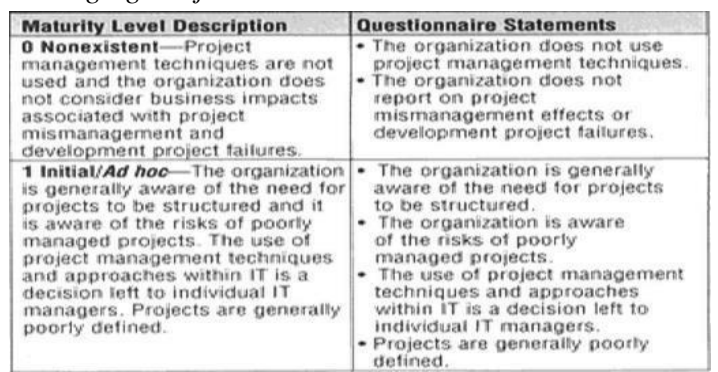

Gambar 2 Contoh Pembuatan Pernyataan - Pernyataan Kuesioner PO10 Managing Projects

Sumber: Andrea Pederiva, The COBIT Maturity Model in a Vendor Evaluation Case, Information Systems Control Journal, Volume 3, 2003, p. 2. 
Untuk mendapatkan nilai pencapaian dari setiap pernyataan maka diajukan pertanyaan: "Berdasarkan kondisi organisasi yang sesungguhnya, seberapa setujukah anda dengan pernyataan - pernyataan berikut?" Lalu disediakan empat jawaban yang memungkinkan yaitu tidak sama sekali, sedikit, cukup banyak, atau sepenuhnya setuju. Setiap jawaban diberikan bobot masing - masing seperti yang tertera pada Gambar 3:

\begin{tabular}{|l|l|}
\hline Agreement with Statement & Compliance Value \\
\hline Not at all & 0 \\
\hline A little & 0.33 \\
\hline Quite a lot & 0.66 \\
\hline Completely & 1 \\
\hline
\end{tabular}

Gambar 3 Nilai Numerik Tingkat Pencapaian

Sumber: Andrea Pederiva, The COBIT Maturity Model in a Vendor Evaluation Case, Information Systems Control Journal, Volume 3, 2003, p. 2

Setelah kuesioner selesai, setiap tingkat kedewasaan akan memiliki satu set pernyataan yang masing - masing memiliki bobot nilainya sendiri. Berikut merupakan contoh dari kuesioner yang sepenuhnya disusun berdasarkan model kedewasaan tingkat ketiga proses PO10 Managing Projects dengan nilai - nilai pencapaian dari setiap pernyataan.

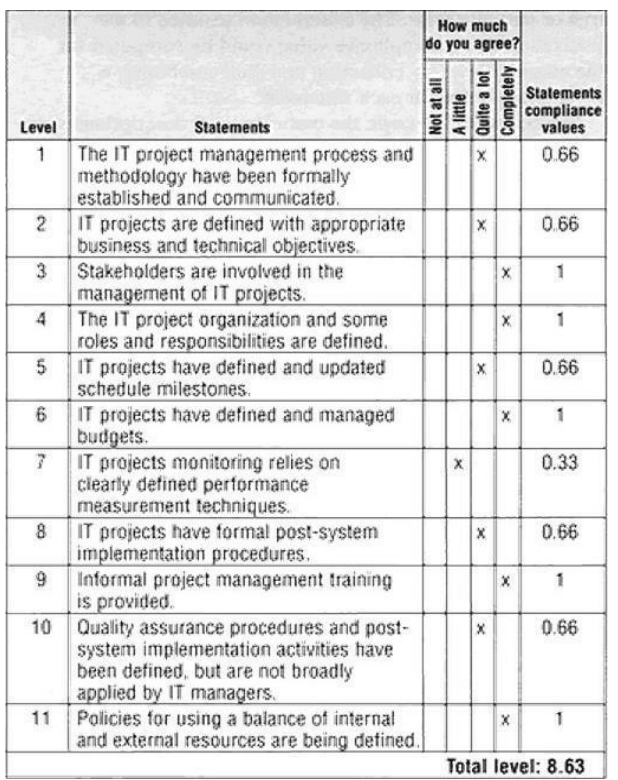

Gambar 4 Kuesioner untuk Model Kedewasaan Tingkat Ketiga Proses PO 10

Sumber: Andrea Pederiva, The COBIT Maturity Model in a Vendor Evaluation Case, Information Systems Control Journal, Volume 3, 2003, p. 3

Dari nilai - nilai pencapaian setiap skenario maka dapat dihitung hasil rata - rata tingkat pencapaian pernyataan pernyataannya. Pada kasus kedewasaan tingkat ketiga ini, berarti $8,63 / 11=0,78$. Begitu pula dengan setiap tingkat kedewasaan lain yang dapat dihitung nilai pencapaiannya mulai dari tingkat kedewasaan nol hingga tingkat kedewasaan kelima seperti yang ditunjukkan pada Gambar 5.

\begin{tabular}{|c|c|c|c|}
\hline $\begin{array}{c}\text { Maturity } \\
\text { level }\end{array}$ & $\begin{array}{c}\text { Sum of statements } \\
\text { compliance values } \\
(\mathbf{A})\end{array}$ & $\begin{array}{c}\text { Number of maturity } \\
\text { level statements } \\
(\mathbf{B})\end{array}$ & $\begin{array}{c}\text { Maturity level } \\
\text { compliance value } \\
(\mathbf{A} / \mathbf{B})\end{array}$ \\
\hline 0 & 0.00 & 2.00 & 0.00 \\
\hline 1 & 0.00 & 9.00 & 0.00 \\
\hline 2 & 3.00 & 6.00 & 0.50 \\
\hline 3 & 8.63 & 11.00 & 0.78 \\
\hline 4 & 6.97 & 9.00 & 0.77 \\
\hline 5 & 6.31 & 8.00 & 0.79 \\
\hline
\end{tabular}

Gambar 5 Perhitungan Pencapaian Nilai Tingkat Kedewasaan Sumber: Andrea Pederiva, The COBIT Maturity Model in a Vendor Evaluation Case, Information Systems Control Journal, Volume 3, 2003, p. 3

Nilai pencapaian dideskripsikan sebagai kontribusi dari setiap skenario tingkat kedewasaan organisasi. Nilai pencapaian dinormalisasikan seperti pada Gambar 6, kemudian total dari tingkat kedewasaan untuk proses - proses yang dihitung dijumlahkan untuk mendapatkan nilai pencapaian dari setiap tingkat kedewasaan seperti pada Gambar 7.

\begin{tabular}{|c|c|c|}
\hline Level & $\begin{array}{c}\text { Not normalized } \\
\text { compliance values } \\
(\mathbf{A})\end{array}$ & $\begin{array}{c}\text { Normalized } \\
\text { compliance values } \\
{[\mathrm{A} / \text { Sum(A)] }}\end{array}$ \\
\hline 0 & 0.00 & 0.000 \\
\hline 1 & 0.00 & 0.000 \\
\hline 2 & 0.50 & 0.176 \\
\hline 3 & 0.78 & 0.275 \\
\hline 4 & 0.77 & 0.272 \\
\hline 5 & 0.79 & 0.237 \\
\hline Total: & 2.84 & 1 \\
\hline
\end{tabular}

Gambar 6 Perhitungan Normalisasi Vektor Pencapaian

Sumber: Andrea Pederiva, The COBIT Maturity Model in a

Vendor Evaluation Case, Information Systems Control Journal, Volume 3, 2003, p. 3

\begin{tabular}{|c|c|c|}
\hline Level & $\begin{array}{c}\text { Normalized } \\
\text { compliance values } \\
(\mathbf{B})\end{array}$ & $\begin{array}{c}\text { Contribution } \\
\left(\mathbf{A}^{*} \mathbf{B}\right)\end{array}$ \\
\hline 0 & 0.000 & 0.00 \\
\hline 1 & 0.000 & 0.00 \\
\hline 2 & 0.176 & 0.35 \\
\hline 3 & 0.275 & 0.83 \\
\hline 4 & 0.272 & 1.09 \\
\hline 5 & 0.277 & 1.38 \\
\hline & Total maturity level: & 3.65 \\
\hline
\end{tabular}

Gambar 7 Perhitungan Total Tingkat Kedewasaan

Sumber: Andrea Pederiva, The COBIT Maturity Model in a

Vendor Evaluation Case, Information Systems Control Journal, Volume 3, 2003, p. 3

Melalui penyusunan kriteria ini, kuesioner yang dibuat selaras sepenuhnya dengan model kedewasaan dan cukup rinci sesuai dengan kebutuhan tingkat kedewasaan. Hal ini berguna untuk mendukung dalam menemukan poin - poin penting yang memungkinkan atau menghambat organisasi mencapai tingkat kedewasaan tertentu. Metode yang telah diterangkan di atas ini dijadikan sebagai pedoman penghitungan nilai audit DS 4, 5, 10, 11, dan 12 di Perpustakaan Universitas Kristen Petra. 


\section{MODEL BISNIS PERPUSTAKAAN UNIVERSITAS KRISTEN PETRA \\ 3.1 Model Bisnis Perpustakaan Universitas Kristen Petra}

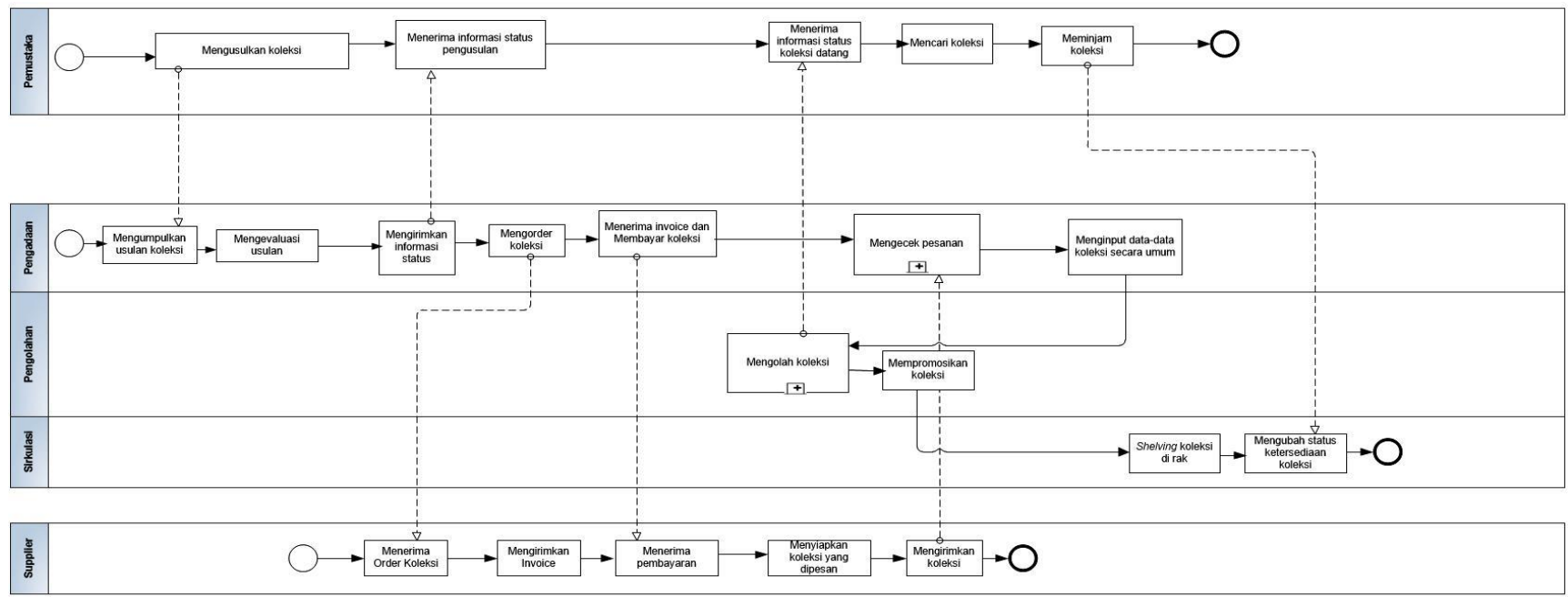

Gambar 8 BPMN Perpustakaan Universitas Kristen Petra

Melalui wawancara diketahui sembilan pilar model bisnis perpustakaan, salah satunya ialah value proposition berupa layanan - layanan yang disediakan perpustakaan terutama yang berhubungan langsung dengan pemustaka, target customer utama di perpustakaan ialah mahasiswa, serta value configuration perpustakaan yang dimulai dari pengusulan, pengadaan, pengolahan, dan sirkulasi koleksi.

\subsection{Target Bisnis dan Strategi Pencapaian}

Sebagai organisasi yang menawarkan layanan sebagai pusat informasi bagi seluruh civitas akademika Universitas Kristen Petra, perpustakaan memiliki peluang ke depan dalam jangka waktu yang panjang menjadi community hub. Perpustakaan dapat menjadi community hub paling tidak untuk internal Universitas Kristen Petra antar dosen, karyawan, dan mahasiswa tapi juga tidak menutup kemungkinan berpotensi untuk orang luar sehingga dapat melingkupi pengabdian masyarakat dan public relation dengan membentuk citra kampus secara keseluruhan.

Dalam mencapai tujuan bisnis itu dibutuhkan strategi yang terdiri dari struktur organisasi dan job description beserta proses bisnis. Struktur organisasi perpustakaan secara umum terdiri dari Kepala Perpustakaan, Kasubag TU, Kepala Bidang Layanan Teknis, dan Kepala Bidang Layanan Pengguna tetapi jika dirinci maka akan seperti pada Gambar 9.
Model proses bisnis memiliki banyak elemen pemodelan misalnya seperti activities, gateways, events, dan flows yang mendeskripsikan keseluruhan proses. Salah satu metode pemodelan proses bisnis ialah dengan menggunakan Business Process Model and Notation yang lebih umum disebut BPMN. Menurut Object Management Group, tujuan utama BPMN ialah untuk menyediakan notasi yang dapat langsung dipahami oleh para pelaku bisnis, mulai dari analis bisnis yang membuat konsep awal proses hingga ke pengembang teknis yang bertanggung jawab menerapkan teknologi untuk menjalankan proses-proses, sampai pebisnis yang mengelola dan mengawasi prosesprosesnya. [5]. Gambar 8 merupakan diagram BPMN yang menunjukkan proses bisnis perpustakan melibatkan tiga bagian utama yaitu Bagian Pengadaan, Pengolahan, dan Sirkulasi serta Supplier dan Pemustaka.

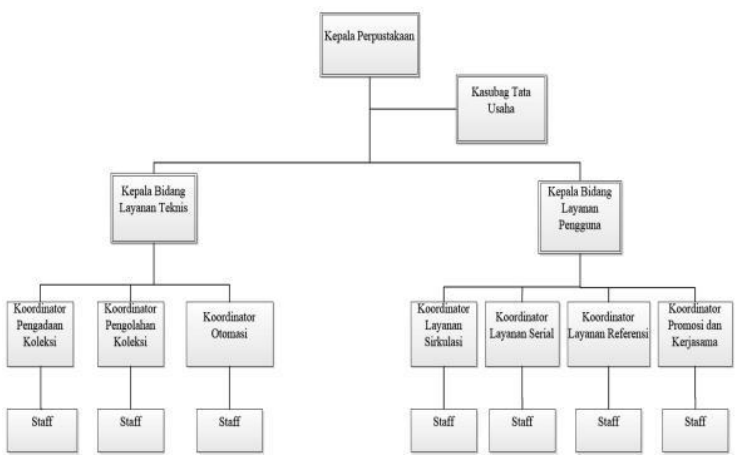

Gambar 9 Struktur Organisasi Internal Perpustakaan 


\subsection{Kondisi TI di Perpustakaan Universitas Kristen Petra}

Proses bisnis perpustakaan tidak lepas dari dukungan TI, yang meliputi kondisi TI ialah dari segi software, hardware, topologi jaringan, hingga kondisi kinerja TI sesungguhnya di lapangan di mana datanya diperoleh dengan cara wawancara dan observasi.

Dilihat dari segi software, Perpustakaan menggunakan iSPEKTRA yaitu sistem informasi perpustakaan yang ditampilkan melalui halaman website. Halaman yang ditampilkan disesuaikan dengan hak akses yang dimiliki penggunanya seperti untuk mengakses modul pengadaaan maka Bagian Pengadaan login dengan memilih akses sebagai pengadaan sedangkan pemustaka hanya dapat mengakses modul catalog.

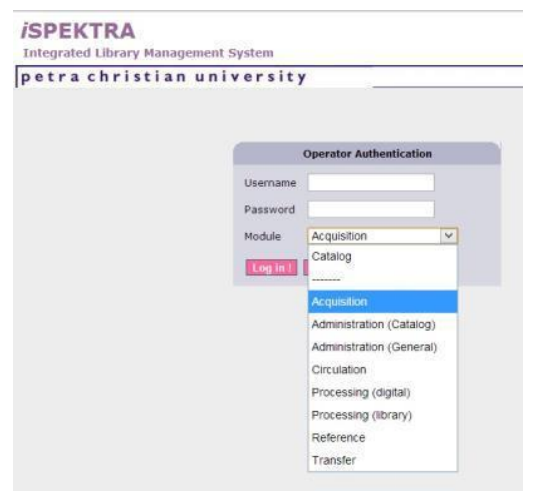

Gambar 10 Halaman Login iSPEKTRA

Hardware yang digunakan di perpustakaan merupakan hasil pengadaan dari Pusat Komputer. Dilihat dari segi hardware, secara umum spesifikasi hardware yang biasanya diadakan oleh Puskom pada umumnya menggunakan Operating System: Microsoft Windows XP atau Microsoft Windows 7, Processor: Intel(R) Core i5, RAM 2GB, dan Total Hard Disk Drive sebesar 500 GB. Sementara komputer terminal memiliki spesifikasi Processor: Core 2 Duo, RAM 1 GB, dan Total Hard Disk Drive sebesar $320 \mathrm{~GB}$.

\section{PENGUMPULAN DATA}

\subsection{Deskripsi Kontrol Delivery and Support Software 4, 5, 10, 11, dan 12}

Tabel 1 Deskripsi Kontrol Delivery and Support Software 4, 5, 10, 11, dan 12

\begin{tabular}{|c|l|}
\hline DS4 & - Perpustakaan mengadakan pelatihan secara teratur untuk \\
Ensure & menghadapi bencana atau gangguan. \\
Continuos & - Perpustakaan memiliki media penyimpanan back up di luar \\
Service & $\begin{array}{l}\text { lingkungan universitas (offsite) } \\
\text { - Perpustakaan memiliki dan meninjau prosedur yang dilakukan } \\
\end{array}$ \\
& setelah berhasil pulih dari bencana atau gangguan \\
\hline
\end{tabular}

Tabel 1 (lanjutan)

\begin{tabular}{|c|c|}
\hline $\begin{array}{l}\text { Manage } \\
\text { Security }\end{array}$ & $\begin{array}{l}\text { - Perpustakaan memiliki IT Security Plan yang mencakup } \\
\text { prosedur dan kebijakan keamanan disertai investasi pada } \\
\text { layanan, personil, software, dan hardware. } \\
\text { - Ada otentikasi dan otorisasi yang berlaku untuk seluruh } \\
\text { karyawan perpustakaan } \\
\text { - Perpustakaan melakukan pengujian dan terhadap keamanan IT } \\
\text { - Perpustakaan mampu menetapkan insiden keamanan, besar } \\
\text { dampaknya terhadap kelangsungan IT, dan cara penanganannya } \\
\text { - Ada perlindungan terhadap teknologi keamanan dan jaringan } \\
\text { - Perpustakaan melindungi keamanan IT dengan pencegahan, } \\
\text { pendeteksian, dan pengoreksian terhadap software perusak } \\
\text { - Perpustakaan memastikan pertukaran data yang sifatnya sensitif } \\
\text { dilakukan melalui media yang aman }\end{array}$ \\
\hline $\begin{array}{c}\text { DS10 } \\
\text { Manage } \\
\text { Problems }\end{array}$ & $\begin{array}{l}\text { - Perpustakaan mengidentifikasi dan mengklasifikasikan masalah } \\
\text { berdasarkan kategori, dampak, kondisi yang mendesak, dan } \\
\text { prioritas. } \\
\text { - Perpustakaan mampu melacak dan mengawasi penanganan } \\
\text { masalah hingga berakhir. } \\
\text { - Perpustakaan memiliki prosedur dalam penyelesaian masalah } \\
\text { - Perpustakaan melakukan tindakan pencegahan untuk mengurangi } \\
\text { masalah pada layanan }\end{array}$ \\
\hline & $\begin{array}{l}\text { - Perpustakaan memiliki aturan pengelolaan data yang baik, } \\
\text { termasuk di dalamnya prosedur pengarsipan data. } \\
\text { - Perpustakaan menggunakandatabase management dengan harga } \\
\text { yang efektif. } \\
\text { - Perpustakaan memiliki prosedur untuk memastikan media } \\
\text { penyimpanannya selalau dapat digunakan dan terintegritas. } \\
\text { - Perpustakaan menerapkan prosedur penghapusan data yang } \\
\text { sifatnya sensitif dan software dari peralatan atau media yang } \\
\text { sudah tidak dipakai agar tidak muncul kembali. } \\
\text { - Perpustakaan memiliki prosedur back up dan pengembalian } \\
\text { sistem, beserta pengujian terhadap media back up. } \\
\text { - Perpustakaan menerapkan prosedur keamanan dalam } \\
\text { pengelolaan data }\end{array}$ \\
\hline $\begin{array}{c}\text { Manage the } \\
\text { Physical } \\
\text { Environment }\end{array}$ & $\begin{array}{l}\text { - Perpustakaan menetapkan desain lokasi untuk penyimpanan alat } \\
\text { - alat IT dengan baik agar dapat mengurangi terjadinya insiden } \\
\text { fisik. } \\
\text { - Perpustakaan dapat memberikan, membatasi dan mencabut akses } \\
\text { terhadap bangunan dan wilayah menurut kebutuhan bisnis dan } \\
\text { saat situasi darurat } \\
\text { - Perpustakaan menetapkan prosedur hak akses supaya tidak } \\
\text { sembarang orang dapat memasuki ruang server. } \\
\text { - Perpustakaan mengadakan pelatihan keamanan, keselamatan, } \\
\text { dan fasilitas terhadap karyawan } \\
\text { - Perpustakaan menggunakan alat khusus untuk mengawasi dan } \\
\text { mengontrol lingkungan fisik } \\
\text { - Perpustakaan melakukan peremajaan fasilitas secara berkala }\end{array}$ \\
\hline
\end{tabular}

Poin - poin deskripsi kontrol DS 4, 5, 10, 11, dan 12 memberikan gambaran umum mengenai hal - hal yang sebaiknya dilakukan untuk menunjang proses TI di perpustakaan. Dengan mengikuti poin - poin deskripsi kontrol, maka dapat disusun pertanyaan wawancara untuk mengetahui kelengkapan proses yang dilaksanakan di perpustakaan guna menunjang penemuan data berkaitan dengan kontrol delivery and support system yang dilakukan di perpustakaan. 
Dalam upaya mendapatkan data yang tepat untuk menjawab kelengkapan DS 4, 5, 10, 11, dan 12 maka narasumber diwawancarai sesuai dengan bidangnya masing - masing, terdiri dari Kepala Perpustakaan, Bagian Otomasi (software dan hardware), dan Bagian Referensi.

Selama proses pengumpulan data dilakukan mulai dari pemahaman proses bisnis hingga temuan kelengkapan kontrol delivery and support system di perpustakaan, untuk menghindari terjadinya bias peneliti maka dibuat transkrip untuk setiap hasil wawancara dengan narasumber. Melalui adanya dokumentasi tertulis, narasumber dapat melakukan validasi atas konsep yang ditangkap oleh Penulis sehingga data yang ditemukan tidak subyektif.

\section{PERHITUNGAN NILAI AUDIT}

Selain membandingkan kondisi TI perpustakaan dengan kelengkapan kontrol yang diinginkan delivery and support system, dibutuhkan pula pengukuran terhadap tingkat kedewasaan/kematangan TI agar dapat diketahui dan dievaluasi sejauh mana kinerja proses - proses TI di perpustakaan. Dalam upaya menilai tingkat kedewasaan TI perpustakaan, disusun kuesioner berdasarkan deskripsi tingkat kedewasaan DS 4, 5, 10, 11 dan 12 dari tingkat 0 hingga 5 yang berisi pernyataan pernyataan berkaitan dengan tingkat kedewasaan yang seharusnya dipenuhi. Contohnya pada DS 5 level 0 yaitu seperti pada Gambar 10.

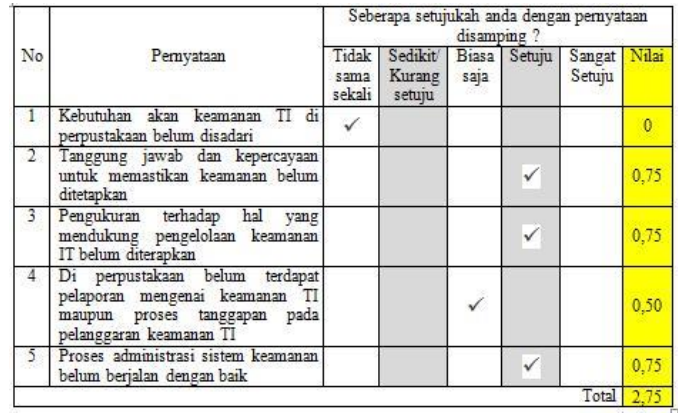

Gambar 10 Kuesioner DS 5 Level 0

Dengan menggunakan metode perhitungan maturity level (lihat bagian 2.4) maka didapatkan nilai audit seperti pada Gambar 11.

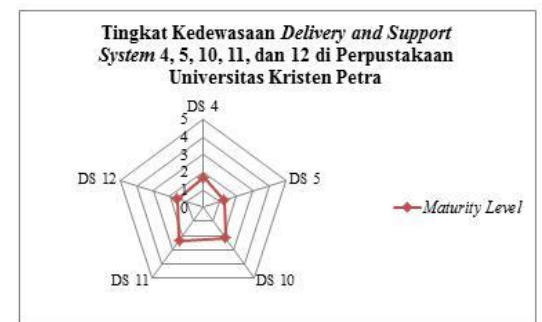

Gambar 11 Hasil Tingkat Kedewasaan Delivery and Support System 4, 5, 10, 11, dan 12

\section{KESIMPULAN DAN SARAN}

Dari penelitian yang dilakukan, ditarik beberapa kesimpulan yaitu:

1. Aspek penilaian kedewasaan TI disesuaikan dengan deskripsi tingkat kedewasaan COBIT 4.0 pada bagian DS 4 , $5,10,11$, dan 12 mulai dari tingkat 0 hingga tingkat 5 . Meskipun layanan yang disediakan oleh Perpustakaan Universitas Kristen Petra yang berkaitan dengan teknologi TI sudah selaras dengan tujuan bisnisnya tetapi tingkat kedewasaan/kematangan layanan TI masih rendah.

2. Hasil penilaian audit diurutkan mulai dari tingkat kedewasaan terendah ialah DS5 Manage Security sebesar 1,28; DS12 Manage the Physical Environment sebesar 1,57; DS4 Ensure Continuous Services sebesar 1,68; DS10 Manage Problems sebesar 2,17; dan DS11 Manage Data sebesar 2,35.

3. Sebagian besar pemicu kecilnya angka kedewasaan TI di perpustakaan disebabkan kurangnya kelengkapan dokumentasi seperti perencanaan dan prosedur tertulis di bidang TI, tidak ada pula catatan riwayat tentang masalah yang pernah terjadi, dan sulit diadakan pengujian serta peninjauan keefektifan isi rencana dan prosedur.

Pada penelitian selanjutnya, diharapkan dalam pengumpulan data sebaiknya dari awal menggunakan tipe wawancara terstruktur yang telah terdiri dari daftar pertanyaan rinci untuk memudahkan penggalian informasi. Selain itu, dibutuhkan informasi yang cukup sebagai landasan awal penelitian.

\section{REFERENSI}

[1] Purwono, Edi. (2004). Aspek - Aspek EDP Audit Pengendalian Internal pada Komputerisasi. Yogyakarta: ANDI.

[2] Gondodiyoto, Sanyoto. (2007). Audit sistem informasi + pendekatan CobIT. Jakarta: Mitra Wacana Media.

[3] IT Governance Institute. (2005). COBIT 4.0: IT Governance Institute.

[4] Pederiva, Andrea. (2003). The COBIT Maturity Model in a Vendor Evaluation Case. Current issues in Information System Control Journal, Volume 3, 2003. http://www.isaca.org/Journal/Past-Issues/2003/Volume3/Pages/The-COBIT-Maturity-Model-in-a-VendorEvaluation-Case.aspx

[5] Object Management Group. (2008). Business Process Model and Notation Version 1.2. [pdf document]. Retrieved from http://www.omg.org/spec/BPMN/1.2/ 